\title{
Gender-based education during clerkships: a focus group study
}

This article was published in the following Dove Press journal:

Advances in Medical Education and Practice

26 February 2014

Number of times this article has been viewed

\section{Lotte van Leerdam \\ Lianne Rietveld \\ Doreth Teunissen \\ Antoine Lagro-Janssen}

Department of Primary and Community Care, Gender and Women's Health, Radboud University Medical Center, Nijmegen, The Netherlands
Correspondence: Antoine Lagro-Janssen Department Primary and Community Care, Gender and Women's Health, Radboud University Medical Center, ELG-II7, PO Box 910I, 6500 HB Nijmegen, The Netherlands $\mathrm{Tel}+3 \mid 243613$ II0

Fax +3। $24354 \mid 862$ Email toine.lagro@radboudumc.nl
Objectives: One of the goals of the medical master's degree is for a student to become a gender-sensitive doctor by applying knowledge of gender differences in practice. This study aims to investigate, from the students' perspective, whether gender medicine has been taught in daily practice during clerkship.

Methods: A focus group study was conducted among 29 medical students from Radboud University, Nijmegen, The Netherlands, who had just finished either their internal medicine or surgical clerkships. Data were analyzed in line with the principles of constant comparative analysis.

Results: Four focus groups were conducted with 29 participating students. Clinical teachers barely discuss gender differences during students' clerkships. The students mentioned three main explanatory themes: insufficient knowledge; unawareness; and minor impact. As a result, students feel that they have insufficient competencies to become gender-sensitive doctors.

Conclusion: Medical students at our institution perceive that they have received limited exposure to gender-based education after completing two key clinical clerkships. All students feel that they have insufficient knowledge to become gender-sensitive doctors. They suppose that their clinical teachers have insufficient knowledge regarding gender sensitivity, are unaware of gender differences, and the students had the impression that gender is not regarded as an important issue. We suggest that the medical faculty should encourage clinical teachers to improve their knowledge and awareness of gender issues.

Keywords: medical education, clerkship, gender, hidden curriculum, clinical teachers

\section{Introduction}

Medical school is the breeding ground for medical knowledge, professional development, and careers, and it includes equal opportunities and gender equality. ${ }^{1}$ Over the last several decades, a significant international body of research on sex and gender differences in health and illness has been developed. This knowledge has to be integrated into medical education and training. "Sex" refers to biological differences between women and men, including chromosomes, sex organs, and hormonal profiles. "Gender" refers to socially constructed and enacted roles and behaviors that occur in a historical and cultural context, and that vary across societies and over time. In medicine, the terms "sex" and "gender" are often used synonymously.

Many recommendations concerning health-related sex and gender differences have already been implemented in the 3-year bachelor of medicine curriculum at Radboud University, Nijmegen, The Netherlands. ${ }^{2}$ The master's program includes 35 months of clinical clerkships and research training, with key clinical clerkships conducted in 
the first 2 years. ${ }^{3}$ One of the aims of the master's program is to become a gender-sensitive doctor by applying knowledge of gender differences in practice. A gender-sensitive doctor approaches men and women as equally significant and valued individuals, while being aware of the gender differences that may occur in biological, as well as in psychological and social aspects of the individual's life experiences. ${ }^{4-6}$ Translating gender differences into actual patient care is important in order to implement gender into medical education. ${ }^{3}$ During the compulsory part of the master's program, for example, students are trained how to approach patients with a history of sexual abuse and to be aware of the influence of abuse in males and females on the patients' mental and physical health.

Hafferty $^{7}$ defines three interrelated components of medical training. First, there is a formal curriculum that consists of learning objectives and curricular elements. Second, there is an informal curriculum, consisting of an interpersonal form of teaching and learning that takes place between the faculty members and students. ${ }^{8,9}$ Finally, there is a hidden curriculum, which includes the transmission of cultural values and attitudes to students through the structure of teaching and the organization of an educational program. ${ }^{10}$ The hidden curriculum is a very important way of learning in the clinical part of medical education.

Over the last few decades, research has disclosed the presence of gender bias and gender differences in various fields of medical education. ${ }^{6,11}$ To implement a gender perspective in medical education, both male and female clinical teachers should be involved, and they should embrace gender aspects as important issues. Clinical teachers involved in clerkship programs play a key role in drawing attention to gender. Most male faculty leaders understand the importance of gender-related issues, but do not recognize gender as an area of significant knowledge and competence in medicine. ${ }^{12}$ Female clinical teachers are more likely than men to consider the physician's gender an important element in consultation, clinical tutoring, and in interactions with colleagues. ${ }^{13}$

Hidden and informal curricula are full of experiences and events that students regard as "teaching them something about professionalism and professional values." ${ }^{14}$ Students can learn positive or negative aspects of professionalism through the hidden curriculum. ${ }^{15}$ E-portfolio analyses among medical students showed that both men and women felt excluded from the curriculum. Male exclusion occurred at the level of skills acquisition (gynecological examinations).${ }^{10}$ Female exclusion was evident through a limited range of career pathways that were suitable or open to women. Gender is, therefore, an important part of professionalism and professional values. ${ }^{16}$

The aim of our study is to gain insights into which types of exposure students in two clerkships receive in terms of gender education in medicine.

\section{Methods \\ Study design}

This was a qualitative study involving focus group interviews.

\section{Participants}

We sent an email to four groups of interns to inform them about our study and to invite them to participate. We conducted four focus group interviews with 29 medical students between August and October 2012. Each focus group consisted of 6-8 students: two groups that had just finished their internal medicine clerkship; and two groups that had just finished their surgical clerkship. The focus group discussions took place 7-9 days after the end of the clerkships. We chose these two specialties because both clerkships are the longest and take 8 weeks to complete, and because gender medicine is of importance in both specialties. ${ }^{11}$ Both clerkships take place in the first year of the master's program of the curriculum. We aimed to distribute male and female students equally in the focus groups to enhance the exchange of opinions and to expose possible gender differences between the students more explicitly. Prior to the focus group interview, the students were asked to fill out a consent form.

We preferred focus group interviews to individual interviews, as they would stimulate group interactions between the participants, which would allow them to explore and clarify their experiences and views in greater depth. ${ }^{17}$ In advance, we assumed that four focus groups - two groups for either type of clerkship - would be sufficient to reach an information saturation point. We intended to conduct additional focus groups if any new items should come up during the last focus group interview. The maximum duration of each session was 75 minutes. All focus group interviews took place at the Faculty of Medical Sciences at Radboud University, Nijmegen, and they were fully audio-taped for the analysis.

\section{Data analysis}

The discussions were attended by a skilled moderator and an observer who were familiar with the topic, and who were about to finish their master's degree in medicine. Following the guidelines for conducting the focus groups, the moderator used an interview guidebook (Table S1). ${ }^{18,19}$ The interview 
guidebook was constructed on the basis of relevant literature and expert opinion. To facilitate the transcription, field notes of the students' non-verbal communication were made by the observer. In-between focus groups, minor adjustments were made to the topic list arising from the students' feedback during the interview. After each session, the audiotapes were transcribed by the moderator. Data were analyzed by two independent reviewers with the help of ATLAS.ti software (version 4.2; ATLAS.ti Scientific Software Development $\mathrm{GmbH}$, Berlin, Germany), and the analyses were in line with the principles of constant comparative analysis. ${ }^{20}$

Two reviewers (LvL, LR) read all the interviews several times to familiarize themselves with the data. First, we used open coding to conceptualize the data, and we subsequently used selective coding to establish the themes. After we had independently analyzed the data, we discussed the initial coding with the supervisor (ALJ). In the event that disagreements arose between the two reviewers, the supervisor was consulted.

Upon consultation, the Ethical Committee of the Radboud University Medical Center stated that ethical approval was not necessary because of the non-invasive nature of the study.

\section{Results}

\section{Characteristics of the study population}

We interviewed 29 students - 15 females (52\%) with a mean age of 23.8 years (standard deviation: 1.5). Of these students, $55 \%$ completed their clerkship in a general hospital and $45 \%$ in a university hospital (Table 1).

All students felt that insufficient attention was being paid to gender during their clerkships. We asked them to mention a situation in which their clinical teachers discussed gender differences during their clerkship. Only a few students could recall such a situation (Table 2). The given examples focused on gender differences in communication, in epidemiology, and in symptom presentation.

Men will present less frequently with unexplained symptoms such as fatigue. I think women would present more often with fatigue with an underlying psychological explanation than men. [F]

Table I Characteristics of the focus groups $(n=23)$

\begin{tabular}{lll}
\hline Mean age in years $( \pm \mathrm{SD})$ & $23.9(\mathrm{I} .6)$ & \\
Gender & Male (48\%) & Female (52\%) \\
Type of clinical clerkship hospital & Academic (52\%) & General (48\%) \\
Phase of study & $\begin{array}{l}\text { Finished internal } \\
\text { medicine (39\%) }\end{array}$ & $\begin{array}{l}\text { Finished surgical } \\
\text { clerkship (61\%) }\end{array}$ \\
\hline
\end{tabular}

Abbreviations: $\mathrm{n}$, number; $\mathrm{SD}$, standard deviation.
Table 2 Situations identified by the students in which the clinical teacher pointed to gender differences

"We talked about the risk factors for cholelithiasis (four Fs) in women." "My clinical teacher told me that irritable bowel syndrome and fibromyalgia have a higher incidence in women."

"During my clerkship at the cardiology department, they told me something about the atypical presentation of women with a myocardial infarction."

"At the oncology department, we talked about different chemotherapy treatments and scalp hypothermia to prevent hair loss in women."

"At the surgery department, I saw a man with gynecomastia. We talked about compensation differences for breast reduction surgery in men and women by health insurance providers."

"In the operation room, we talked about incision techniques in abdominal surgery. Cosmetics is more important in women than in men."

"An orthopedist told me to be alert to knee complaints in young women, as these complaints are often stress-related without underlying diseases."

"Different differential diagnosis in women with abdominal pain and suspected appendicitis."

"My clinical teachers discussed a gender difference in patients with aneurysm. Women have a four times higher risk of rupture than men with the same aneurysm diameter."

"One of the surgeons told me that obese women are easier to operate on than obese men because men are more likely to have adipose tissue around their internal organs."

During my clerkship at the cardiology department, they told me something about the atypical presentations of women with a myocardial infarction. [F]

Most students stated that the topic of gender had barely been discussed by their clinical teachers during their clerkships. The students suggested several reasons why they experienced little attention to gender medicine, which can be referred in to three themes: insufficient knowledge; unawareness; and minor impact.

\section{Insufficient knowledge}

Some students mentioned that their clinical teachers lacked knowledge of gender differences, and that this contributed to the low transfer of gender-related knowledge from clinical teachers to the students throughout their clerkships.

Maybe that some physician teachers find it not important enough to mention. I also think that a lot of physicians don't have enough knowledge about gender differences either. [F]

I don't think our clinical teachers have enough knowledge of gender differences and so they can't transfer and teach it to the students. [F]

All students stated at the time of the interviews that they lacked sufficient knowledge about gender-specific medicine 
and gender differences. As a result, they did not actively ask about such differences because they did not know which issues required specific attention. Most students were familiar with an atypical presentation of chest pain in women with angina pectoris, or with the higher incidence of cholelithiasis in women. However, gender differences in heart failure and psychiatric diseases, for example, were not mentioned because the students were neither aware of the differences in symptoms, the course of the symptoms, the associated complications, nor of the impact on the quality of care:

"I don't actively ask questions about gender differences because my knowledge is lacking." [F]

None of the students reported that they discussed any sex differences in pharmacotherapy (for example, concerning the effectiveness or side effects of drugs). Although all students underscored the importance of having an awareness of gender differences in diagnostics and treatment, two students cautioned that too much attention might lead to stereotyping.

It's important to have adequate knowledge of gender differences, but I think that you shouldn't exaggerate it because you might treat patients differently in advance, purely on the basis of their biological sex. [M]

\section{Unawareness}

Several students also mentioned a level of unawareness of gender differences among clinical teachers and themselves, along with clinical teachers' weak interest in gender differences in general. This will contribute, as the students say, to the low level of attention being paid to gender differences.

When I discuss a patient with my physician teacher we talk about basic things; during the minutes that follow you can ask some questions yourself but I've never experienced that the physician will discuss gender differences. [F]

Physicians are not aware of the differences. To be honest, I almost never think about it myself either. I think this also goes for our clinical teachers. [M]

Some students noticed that female physicians were more likely to take gender differences into account than their male colleagues.

I think that female physicians are more aware than male physicians, I don't know why but I think that women would take gender differences into account more rapidly. [M]

Approximately half of the students mentioned that physicians working in a university hospital alerted students to gender issues more often than did physicians working in a general hospital, because there is more time available for education in the university hospital setting.

Lastly, the students spontaneously discussed the influence of the teacher's age in attention to gender. The opinions were divided as to whether young or old physicians are more "gender-minded." The proponents for the younger physicians argued that nowadays, a growing, gender-sensitive domain of evidence-based knowledge exists that cannot be overlooked. Most students were in favor of the elderly physicians because of their practicebased experiences.

I think age plays an important role. The older you are, the more experienced you are. When something went wrong, you will be more alert and you will never forget it. I think that older physicians have gained more insight in gender differences than younger physicians. [F]

\section{Minor impact}

The participating students came to the conclusion that because gender, in the eyes of the clinical teacher, does not make any difference to diagnosis and therapy, and because clinical teachers showed little interest in research about gender differences, gender medicine evoked an assumption that it had a minor impact.

I think that clinical teachers subconsciously don't find gender differences important. They would rather stress the need for students to recognize medical symptoms and disease. That's why they're unaware of gender differences. They do discuss the characteristics of heart failure but never gender differences in patients with heart failure. [M]

It (gender) will not influence your diagnostic and therapeutic management. [M]

Some students, following their surgery clerkship, said that clinical teachers in surgery found that gender differences were not important in clinical medicine because it definitely did not influence or change the diagnostic and therapeutic management.

I think that it's different in surgery than in internal medicine or family medicine. In surgery, they put less focus on gender differences because the question is: are we going to operate or not? [F]

When you have a patient of a certain age with a particular symptom, you will perform a standard examination. It doesn't matter whether it's a male or female patient: you'll do it anyway. [M] 


\section{Discussion}

Our study shows that medical students at our institution perceive that they have received limited exposure to genderbased education after completing key clinical clerkships. The reasons why gender differences are not discussed during their clerkship can be clustered into three main themes: insufficient knowledge; unawareness; and minor impact. As a result, the students feel that they have insufficient knowledge and competencies to become gender-sensitive doctors.

\section{Comparison with existing literature}

All our interviewees found that gender was important. The minor impact and level of unawareness of gender differences, from the medical teacher's perspective, was also found in other studies. ${ }^{1,3,12}$ A semi-structured interview study conducted with 20 male education leaders from Sweden showed that all informants regarded gender as important, but of low status. ${ }^{12}$ The reasons why they did not find gender important included a lack of time, overexposure of the topic of gender, and the obviousness of gender. The respondents also indicated that providing gender-based education was not an easy task because of insufficient knowledge, lack of awareness, and prejudiced attitudes of the teachers. Some of these reasons, especially a lack of knowledge and awareness, were also mentioned by the students that participated in our study.

A Swedish study ${ }^{21}$ conducted among 243 clinical teachers illustrated that many respondents (men to a greater degree than women) minimized the importance of gender by declaring that something else was more important. It might be especially important to increase gender awareness in the surgical clerkship because it is known that more family physicians and non-surgical doctors, as compared to surgical doctors, agreed that gender was important in their professional relationships. ${ }^{1}$

Some students believe that older physicians, or physicians working in a university hospital, alert students earlier and more often than younger physicians or physicians working in a general hospital. This finding is contrary to the results reported in literature, which concluded that specialty, age, academic degree, and number of years in the profession do not interfere with the physicians' attitudes towards the importance of gender. ${ }^{1,13}$

Approximately $65 \%$ of the students we interviewed thought that female physicians took gender differences into consideration more often than male physicians. In addition, the students experienced that female physicians taught about gender differences more often than did male physicians. According to the literature, senior female physicians are more likely than their male partners to consider the physician's gender of importance in consultation, in clinical tutoring, in contacts with colleagues and staff, and in research. ${ }^{1}$ Most students assumed that physicians performed equal physical examinations and additional research for both male and female patients. However, several studies have shown that female patients are not treated equally, and that they often receive diagnostics and treatments that differ from those of male patients. ${ }^{22}$ Women also remain underrepresented in biomedical research. Despite the obvious physical and physiological differences between men and women, drugs are rarely prescribed with these variations in mind. ${ }^{23}$ Students need to know that patients receive substandard care on the basis of their biological sex so as to be aware of gender bias.

\section{Strengths and limitations of this study}

Qualitative research is an appropriate method for exploring the experiences and thoughts of medical students on the importance of gender throughout their medical education. We chose focus group interviews to reveal the dimensions of understanding that often remain untapped by more conventional data collection techniques. However, participants in focus group interviews may influence each other in their discussions, and such group dynamics may silence individual opinions and stimulate group norms. ${ }^{17}$ The results also depend on the memory and recall of the students regarding incidents in their clerkship, despite the short amount of time that passed between the focus group discussion and the end of the clerkships. Moreover, the results depend on the respondents' willingness to give examples and explanations. In composing the focus groups, we aimed to achieve an equal distribution of male and female students which, with 14 male students and 15 female students, was almost successful. To reach an optimum variety of opinions, we used the purposive sampling strategy, and the number of participants in this study was considered adequate for this strategy. ${ }^{24,25}$ The focus groups were conducted in the Dutch language.

\section{Implications for medical education}

Gender research is gaining importance as the medical research that focuses on the differences between men and women. Applying a gender perspective means that inequalities and differences need to be understood, described, and analyzed within their sociocultural context. ${ }^{26}$ Many physicians are either unaware of the existence of gender differences beyond hormonal differences, or they fail to see that gender differences have an impact on their patients' health. ${ }^{6,11,16}$ In 
everyday practice, physicians apply what they have learned, which is to diagnose and treat uniform bodies. The knowledge of differences between men and women in medical textbooks is scarce. ${ }^{11}$ The deeply rooted dominant idea is that medicine is about people, not about men or women. The principle of neutrality presupposes that, with the exception of reproduction, biological processes are the same in women and men. The failure to recognize and acknowledge the importance of gender differences gives rise to gender bias: the assumption that what goes for the one sex also goes for the other. Unfortunately, this assumption may give rise to toxic side effects. Out of the ten drugs that were banned by the US Food and Drug Administration between 1997 and 2001 for the seriousness of their side effects, there were eight that mainly showed side effects in women. ${ }^{27}$

Given that the normal body is conceived of as a male body, usually a white male body, men are considered as normal and as normative; women then deviate from the norm.

Our study implicates that clinical teachers may have insufficient knowledge of health-related gender issues, and teacher training on this issue is extremely important. It is essential for the next generation of physicians that the present generation of clinical teachers passes on their knowledge of gender differences to their medical students.

There is an ongoing debate in medical education about the effective ways to define, develop, and measure professional behaviors. Peer assessment of professional behaviors has proven to be an effective mechanism for measuring professional behaviors. ${ }^{28}$ As medical students interact with each other frequently and know each other well, they are in a unique position to provide valid assessments of behavior. ${ }^{29}$ A focus group interview conducted among 30 medical students in the United Kingdom showed that peer assessment can offer valuable feedback on professional behaviors, as part of a formative reflection process. ${ }^{28}$ However, research indicates that medical schools have different requirements and mechanisms for providing feedback, so it remains a key challenge for the medical schools to integrate peer assessment effectively.

Our study suggests that the medical faculty should encourage clinical teachers to improve their knowledge and awareness of gender. The students participating in this study said they would appreciate having more education on gender differences, especially in terms of gender differences in clinical presentation and treatment during their clerkships. To make sure that the implementation of gender issues will not meet any major resistance, we need to convince education managers and clinical teachers that gender issues in medicine are scientifically important. It is crucial to minimize gender blindness and andronormativity because these are major impediments to securing greater exposure to gender issues. ${ }^{1}$

The results of our study are based on a relatively small number of students, so we have to interpret our results cautiously. Nevertheless, we have a strong feeling, based on our insight into and experiences with the medical culture at teaching hospitals, that our findings are not very different from the situation in other medical schools. Further multicenter studies have to demonstrate that we may extrapolate the results to other medical universities in The Netherlands, as well as internationally.

\section{Conclusion}

All participating students felt that they did not have enough knowledge and experience to become gender-sensitive doctors. In addition both students' and clinical teachers' unawareness of gender differences contributes to a low level of attention being paid to gender issues during clerkship programs. All students believe that it is necessary to implement gender medicine in the clinical phase of medical education because this phase of education plays an important role in the process of becoming a gender-sensitive doctor. Our study suggests that the medical faculty should encourage clinical teachers to improve their knowledge and awareness of gender.

\section{Disclosure}

Lotte van Leerdam is a trainee GP at the Radboud University Medical Center. Lianne Rietveld is in vocational training in psychiatry at the Radboud University Medical Center. Doreth Teunissen, GP, PhD in medicine, is a senior researcher at the Gender and Women's Health Unit at the Radboud University Medical Center. Antoine Lagro-Janssen, GP, PhD in medicine, holds a professorship in Women's Health. She is the head of the unit of Gender and Women's Health at the Radboud University Medical Center in The Netherlands. The authors report no other conflicts of interest in this work.

\section{References}

1. Risberg G, Hamberg K, Johansson EE. Gender awareness among physicians - the effect of specialty and gender. A study of teachers at a Swedish medical school. BMC Med Educ. 2003;3:8.

2. Verdonk P, Mans LJ, Lagro-Janssen AL. Integrating gender into a basic curriculum. Med Educ. 2005;39(11):1118-1125.

3. Verdonk P, Benschop YW, De Haes JC, Lagro-Janssen AL. Making a gender difference: case studies of gender mainstreaming in medical education. Med Teach. 2008;30(7):e194-e201. 
4. Iedema R, Degeling P, Braithwaite J, Chan DKY. Medical education and curriculum reform: putting reform proposals in context. Med Educ Online. 2004;9:17.

5. Verdonk P, Benschop Y, de Haes H, Mans L, Lagro-Janssen T. 'Should you turn this into a complete gender matter?' Gender mainstreaming in medical education. Gend Educ. 2009;21(6):703-719.

6. Lagro-Janssen AL. [Sex, gender and health: developments in scientific research]. Ned Tijdschr Geneeskd. 2007;151(6):374-378. Dutch.

7. Hafferty FW. Beyond curriculum reform: confronting medicine's hidden curriculum. Acad Med. 1998;73(4):403-407.

8. Pingleton SK, Davis DA, Dickler RM. Characteristics of quality and patient safety curricula in major teaching hospitals. Am J Med Qual. 2010;25(4):305-311.

9. Ozolins I, Hall H, Peterson R. The student voice: recognising the hidden and informal curriculum in medicine. Med Teach. 2008;30(6): 606-611.

10. Van den Einden L, te Kolste M, Lagro-Janssen ALM, Dukel L. "I'11 just do this one." - The role of physicians in disallowing medical students to perform gynecological examinations. Acad Med. 2014; 89:77-83.

11. Dijkstra AF, Verdonk P, Lagro-Janssen AL. Gender bias in medical textbooks: examples from coronary heart disease, depression, alcohol abuse and pharmacology. Med Educ. 2008;42(10):1021-1028.

12. Risberg G, Johansson EE, Hamberg K. 'Important. .. but of low status': male education leaders' views on gender in medicine. Med Educ. 2011 45(6):613-624.

13. Risberg G, Johansson EE, Westman G, Hamberg K. Gender in medicine - an issue for women only? A survey of physician teachers' gender attitudes. Int J Equity Health. 2003;2(1):10.

14. Karnieli-Miller O, Vu TR, Holtman MC, Clyman SG, Inui TS. Medical students' professionalism narratives: a window on the informal and hidden curriculum. Acad Med. 2010;85(1):124-133.

15. Gaufberg EH, Batalden M, Sands R, Bell SK. The hidden curriculum: what can we learn from third-year medical student narrative reflections? Acad Med. 2010;85(11):1709-1716.
16. Lagro-Janssen AL. [Medicine is not gender-neutral: influence of physician sex on medical care]. Ned Tijdschr Geneeskd. 2008;152(20): 1141-1145.

17. Kitzinger J. Qualitative research. Introducing focus groups. BMJ. 1995;311(7000):299-302.

18. Krueger RA. Is it a focus group? Tips on how to tell. J Wound Ostomy Continence Nurs. 2006;33(4):363-366.

19. Krueger RA. Analyzing focus group interviews. J Wound Ostomy Continence Nurs. 2006;33(5):478-481.

20. Glaser B, Strauss A. The Discovery of Grounded Theory: Strategies for Qualitative Research. Chicago, IL: Aldine Publishing Company; 1967.

21. Risberg G, Johansson EE, Westman G, Hamberg K. Attitudes toward and experiences of gender issues among physician teachers: a survey study conducted at a university teaching hospital in Sweden. BMC Med Educ. 2008;8:10.

22. Rathore SS, Chen J, Wang Y, Radford MJ, Vaccarino V, Krumholz HM. Sex differences in cardiac catheterization: the role of physician gender. JAMA. 2001;286(22):2849-2856.

23. Kim AM, Tingen CM, Woodruff TK. Sex bias in trials and treatment must end. Nature. 2010;465(7299):688-689.

24. Krueger RA, Casey MA. Focus Groups - A Practical Guide for Applied Research. 4th edition. Thousand Oaks: SAGE Publications, Inc; 2009.

25. Mays N, Pope C. Rigour and qualitative research. BMJ. 1995; 311(6997):109-112.

26. Hammarstöm A. Why feminism in public health? Scand J Public Health. 1999;27(4):241-244.

27. Soldin OP, Mattison DR. Sex differences in pharmacokinetics and pharmacodynamics. Clin Pharmacokinet. 2009;48(3):143-157.

28. Garner J, McKendree J, O’Sullivan H, Taylor D. Undergraduate medical student attitudes to the peer assessment of professional behaviours in two medical schools. Educ Prim Care. 2010;21(1):32-37.

29. Kovach RA, Resch DS, Verhulst SJ. Peer assessment of professionalism: a five-year experience in medical clerkship. J Gen Intern Med. 2009;24(6):742-746. 


\section{Supplementary material}

Table SI Focus group interview guidebook

Can you mention a situation in which your teacher discussed gender differences?

Can you imagine a situation in which the teacher paid no attention to gender differences, but where it would have been important to do so? Do you think it is important to be aware of gender differences in sickness and health? Explain.

Do you believe that your clinical teacher has enough knowledge of gender differences? Explain.

Do you think the type of clerkship hospital, clinical teacher, or specialty matters to the degree of attention that is being paid to gender differences? Do you currently have sufficient competencies to become a gendersensitive doctor?

\section{Publish your work in this journal}

Advances in Medical Education and Practice is an international, peerreviewed, open access journal that aims to present and publish research on Medical Education covering medical, dental, nursing and allied health care professional education. The journal covers undergraduate education, postgraduate training and continuing medical education including emerging trends and innovative models linking education, research, and health care services. The manuscript management system is completely online and includes a very quick and fair peer-review system. Visit http://www.dovepress.com/testimonials.php to read real quotes from published authors.

Submit your manuscript here: http://www.dovepress.com/advances-in-medical-education-and-practice-journal 